\title{
Psychological correlates of anxiety in response to COVID-19 outbreak among Iranian University students
}

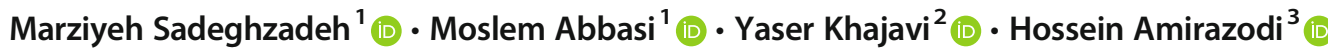

Accepted: 26 November 2020 / Published online: 6 January 2021

(C) The Author(s), under exclusive licence to Springer Science+Business Media, LLC part of Springer Nature 2021

\begin{abstract}
The present study aimed to investigate the psychological factors associated with anxiety in response to the COVID-19 pandemic among Iranian university students. Two hundred and sixty-four (264) students of an Iranian university answered an electronic online questionnaire from 11 through 18 March 2020. The electronic questionnaire included six subscales namely, the Corona Anxiety Inventory, the Anxiety Sensitivity Index, the Social Trust Questionnaire, the Health Anxiety List, the Corona Facts Quiz, and the Trust in National Action in The Face of Corona Inventory. The results of regression analysis showed that the general health concern, the physical component of anxiety sensitivity, and knowledge related to corona facts were significantly associated with anxiety caused by the COVID-19 outbreak. However, belief in honesty at the community level and confidence in national measures taken against Corona were significant negative predictors of anxiety caused by the COVID-19 outbreak. The findings have implications for countries involved with the COVID-19 pandemic on how to implement their health programs.
\end{abstract}

Keywords COVID-19 · Anxiety · Iranian university students · General health

\section{Introduction}

With the advent of the SARS-CoV-2 virus in various countries around the world, it became clear that the prevalence of the virus was different from that of any other similar epidemics, such as Zika, Ebola, swine flu, or SARS. It seems that the high incidence rate of coronavirus disease of 2019 (COVID-19), along with the lack of an effective vaccine, to

Marziyeh Sadeghzadeh sadeghzadeh.mr@gmail.com

$\triangle$ Moslem Abbasi

Abbasi@kazerunsfu.ac.ir

Yaser Khajavi

yaserkhajavi@gmail.com

Hossein Amirazodi

Hossein.kazeroon@gmail.com

1 Department of Psychology, Faculty of Letters and Humanities, Salman Farsi university of Kazerun, Kazerun, Fars, Iran

2 Department of English, Faculty of Letters and Humanities, Salman Farsi university of Kazerun, Kazerun, Fars, Iran

3 Department of Urban Planning, Faculty of Arts and Architecture, Yazd University, Yazd, Iran date (World Health Organization (WHO), 2020), has led to the emergence of emotional experiences in individuals which can rightly be called Corona anxiety.

As far as anxiety caused by the spread of a virus is concerned, studies such as Blakey and Abramowitz (2017), Blakey, Reuman, Jacoby, and Abramowitz (2015), Wheaton, Abramowitz, Berman, Fabricant, and Olatunji (2012) and Xie, Stone, Zheng, and Zhang (2011) have addressed four viruses, namely, Zika, Ebola, Swine flu and SARS. Although it is clear that the state of anxiety about people with COVID-19 and its predisposing factors is very complex and somewhat ambiguous, given the global prevalence and daily increase in patients, it seems that similar to the previous cases, there are two series of factors that contribute to the anxiety caused by the virus: The first is readiness or emotional potential that one has to experience similar anxieties, and the second is the belief or knowledge that people have about facts regarding the virus. First category variables such as personality attributes, psychological distress (prior level of anxiety, depression, and stress), anxiety sensitivity, and health anxiety tend to increase the risk of contracting a disease. Among these variables, health anxiety and anxiety sensitivity are considered as two variables that most likely play a role in causing anxiety relating to the spread of several viruses (Wheaton et al., 2012). 


\section{First Category Variables: Health Anxiety and Anxiety Sensitivity}

Health anxiety refers to a disproportionate or exaggerated concern that a person may experience about his/her health status. Based on the cognitive-behavioral model of Salkovskis and Warwick $(1986,2001)$, this anxiety stems from inefficiencies and assumptions that a person has in mind about the prevalence and spread of diseases, the mental meaning of physical symptoms, and the course and treatment of diseases. These beliefs may remain covert in the unconscious mind and have the potential to be reactivated by a wide range of events, such as receiving news about a relative being infected with a particular illness, media coverage of an illness, or feeling or perceiving a particular change in the body (Marcus, Gurley, Marchi, \& Bauer, 2007). Activation of these beliefs also leads to an over-estimation of the likelihood and severity of disease by individuals, which may ultimately lead to health anxiety (Becker \& Janz, 1984).

On the other hand, anxiety sensitivity is defined by Reiss and McNally (1985) as the fear of arousal-related sensations. This kind of fear arising from beliefs suggests that experiencing arousal may have severe consequences such as death, madness, or social exclusion. Therefore, anxiety sensitivity acts as an anxiety enhancer and leads the person to always listen to the signs of arousal and ultimately experience more anxiety (Taylor et al., 2007). In addition, individuals with high levels of anxiety sensitivity constantly monitor their physical changes, and as a result may show a more severe anxiety response to the spread of various diseases (Blakey \& Abramowitz, 2017).

As mentioned, health anxiety and anxiety sensitivity are among the variables that have been identified as effective in arousing anxiety in the face of a virus outbreak (e.g. Blakey et al., 2015; Wheaton et al., 2012) and can be categorized as the first category regarding a person's previous preparation for outbreak anxiety.

\section{Anxiety and the Second Category of Effective Factors}

The second group of factors that are considered in anxiety caused by the spread of a virus can be attributed to the belief or knowledge that arises from the facts related to that virus in people's minds (Blakey \& Abramowitz, 2017). In a study conducted by Blakey and Abramowitz (2017), people's knowledge of the facts published by the Centers for Disease Control and Prevention was reported as one of the significant predictors of anxiety caused by the spread of Zika. Also, experts such as Taylor and Asmundson (2004) maintain that public awareness of the prevalence of a disease, even for those who are physically healthy, is disturbing. In the same vein, Xie et al. (2011) also emphasize that as a disease spreads, people will inevitably become more aware of the issue, both as a result of direct and close experience and as a result of the information provided by the media. In either case, their anxiety level experiences a sharp increase. Anxiety felt by a person being exposed to the indirect experience of a disease outbreak through media can cause the same or even further anxiety that another person feels through direct experience of the illness. Therefore, information about the disease (whether true and accurate or incorrect and non-scientific), can be accepted as the second category of effective factors in arousing anxiety due to a virus outbreak.

Of course, some of the anxiety caused by the outbreak of a virus must be logically attributed to the characteristics of the disease. In particular, differences in transmission of different viruses can be expected to differentiate between the relationships between psychological structures and the anxiety caused by their prevalence (Liao, Cowling, Lam, \& Fielding, 2011). Therefore, it seems that considering the specific situation that has been created in the face of the COVID-19 pandemic, the possibility of the influence of the third group of factors should be considered besides the previous two categories.

\section{COVID-19 and the Third Group of Effective Factors}

This third category can be related to the speed of spread and high rate of infection of this virus, the wide geographical extent of the infection, and also the need for extensive government intervention in preventing and controlling its spread.

The SARS-CoV-2 virus, in a short period, confronted the international community with a situation that was completely unprecedented and turbulent (Shigemura, Ursano, Morganstein, Kurosawa, \& Benedek, 2020). Isolation, quarantine, and social distancing were suggested as essential to prevent the spread of the disease (Brooks et al., 2020; Wilder-Smith \& Freedman, 2020). But the adoption of such strategies by most governments in the world, due to their psychological effects (Brooks et al., 2020; Xiong et al., 2020), has made the need for cooperation of different social groups with governments in implementing the recommended health policies quite essential.

A review of previous research shows that people's cooperation with officials in following health policies depends on their trust in those who have set such policies (Larson \& Heymann, 2010). According to Larson and Heymann (2010), in situations where risk and uncertainty increase, public confidence is the priority. Because a lack of public trust may not only defeat all health programs but also have very detrimental consequences. Besides, research conducted on the relationship between public health and public trust (e.g., Blair, Morse, \& Tsai, 2017; Marlow, Waller, \& Wardle, 2007; Whetten et al., 2006; Salmon et al., 2005) recommends increasing public confidence as a definite necessity for achieving major health goals. This may be even more important as the COVID-19 pandemic makes the need to cooperate with 
government policies a serious necessity. In fact, it is possible that a lack of public trust in a community greatly reduces the likelihood of success in controlling the prevalence of this new pandemic (Pramiyanti, Mayangsari, Nuraeni, \& Firdaus, 2020) and may even be a new source of anxiety in the society. Such a possibility would mean that a third set of variables would also play a role in people's anxiety in response to the COVID-19 outbreak. This third category, which can be summarized as "social cooperation and trust", seems to be the same variables that are needed in social participation and cooperation with government policies in the face of corona disease. As such, variables such as trust in government and social trust (trust of individuals in a community to each other) can be placed in this third category.

Although the impact of these variables on triggering anxiety due to an outbreak of disease has not been considered yet, previous research has shown the impact of such variables on individuals' adherence to health policies. In particular, trust in the government has been identified as an important factor in citizens' adherence to health policies, restrictions, and guidelines. As Larson and Heymann (2010) point out, distrust in government has become an obstacle to vaccination programs in countries such as the United States, Britain, France, and Nigeria. Blair et al. (2017) also report distrust in the government as a major barrier in controlling disease outbreaks.

At least in case of anxiety caused by the SARS-CoV-2 virus among individuals, two categories of social trust and trust in government should be considered as complementary issues. Trust in the government, in particular, has been identified as an important factor in the citizens' adherence to public health policies, restrictions, and guidelines (Blair et al., 2017) and various studies have mentioned distrust in governments' health policies as a major obstacle in implementing health programs. For example, Blair et al. (2017) found that people who had less confidence in the Liberian government's health policies at the time of the Ebola outbreak were less cautious in their homes and less likely to receive social health advice. Also, a study by Salmon et al. (2005) at the time of the Measles outbreak in California also found that one of the factors influencing parents' refusal to vaccinate children at that time was their distrust in the government's health policies.

Nevertheless, recent research by Pramiyanti et al. (2020) has once again raised distrust in governments as a barrier. As their research shows, at a time when controlling the outbreak of COVID-19 pandemic has become a major issue in the international community, only $8 \%$ of those surveyed trusted their governments' published information on COVID-19. Although this statistic refers to the situation in an Asian country (i.e. Indonesia), with a more or less similar situation, it may become a reason for more anxiety among groups of people.

On the other hand, given the pervasive range of socioeconomic effects posed by the prevalence of the SARS-CoV-2 virus to the global community (Evans, 2020), social trust has also been considered as a possible predictor of anxiety caused by the virus. Social trust is referred to as the "psychoanalyst" of various issues in a society, which can guide individual behaviors in critical situations and increase the likelihood of effective participation in achieving the goals of that society (Chen \& Wan, 2019). Moreover, relying on social trust can reduce some of the ambiguity or uncertainty in a situation, and reducing the complexities of a critical situation can, in turn, lead to the activation of appropriate coping strategies in individuals (Welch et al., 2005), which may ultimately reduce people's anxiety about the crisis. Therefore, it would not seem logical to only consider the two groups of factors that have previously been considered in the study of anxiety caused by certain viruses (such as Zika, Ebola, Swine flu, and SARS) in the study of anxiety caused by COVID-19.

The results of research supporting this idea are gradually being published. In his study, Lovari (2020) focuses on reducing the uncertainty and confusion caused by the outbreak of COVID-19 by improving social trust in Italy. In addition, the study by Bauer et al. (2020) shows that in the German adult society, the amount of social support that a person perceives at the time of COVID-19 has effectively and beneficially contributed to their mental health status. In the United States, a study by Killgore, Taylor, Cloonan, and Dailey (2020) of 1004 adults found that those who perceived more social support from people around them also had far greater psychological resilience in the face of being forced to stay at home during COVID-19 outbreak.

\section{The Present Study}

The present study was conducted shortly after the closure of Iranian universities due to the prevalence of COVID-19 and aimed to investigate the variables associated with Iranian university students' anxiety in response to the COVID-19 pandemic. More specifically, the aim of the present study is to investigate the relationships between Iranian students' anxiety from the prevalence of Coronavirus with health anxiety and anxiety sensitivity (first category variables), published knowledge about corona facts (second class variables), and social trust and trust in national action in the face of coronavirus (third-group variables).

\section{Method}

\section{Participants}

Two hundred and sixty-four (264) students at Salman Farsi University of Kazerun expressed their interest in participating in the study after it had been advertised on the university's Instagram page. The average age of the participants was 20.45 years (SD: 2.28 ) and $37 \%$ of the participants were male 
and $63 \%$ were female. They were studying in three faculties, namely, faculty of letters and humanities, faculty of basic sciences, and faculty of technical sciences and engineering. Students' major was not the focus of this study. It is worth mentioning that the face-to-face classes of the university were canceled on March 2, 2020, to prevent the prevalence of COVID-19 and students lived with their families at the time of collecting the data for the present study. They were also studying the courses through virtual classes and LMS.

\section{Procedure}

To collect the data of the present study, the electronic version of the questionnaires that will be introduced below was placed in the form of a link on one of the Instagram pages of an Iranian university, and students were invited to participate in the research voluntarily. Consent forms were obtained from the participants at the outset of the study. From March 11 through March 18, 2020, a total of 270 university students answered questions included in the research tools. Six of these students were excluded from the data analysis process as they acknowledged that at the time of collecting the research data, someone close to them was infected with the SARS-CoV-2 virus. They were excluded from the analysis process because they were identified in the data screening process as outlier data.

\section{Measures}

\section{Corona Anxiety Inventory}

The inventory is based on questions used in research by Blakey and Abramowitz (2017), Blakey et al. (2015), and Wheaton et al. (2012) to measure anxiety about three viruses: Zika, swine flu pandemic, and Ebola. Overall, the tool has 9 items, all coded on a five-point Likert scale from "not at all" equivalent to 1 to "very much" equivalent to 5 . Among the items of this tool are the following: "To what extent are you concerned about the Coronavirus?" and "How concerned are you that someone you know couldbecome infected with Coronavirus?". The internal consistency of these items in Blakey and Abramowitz's (2017) and Blakey et al.'s (2015) research has been reported to be 0.84 and 0.85 , respectively. In the present study, the value of Cronbach's alpha for this instrument was equal to 0.80 . The McDonald omega value for this tool was also calculated to be 0.81 Also, the correlation coefficient of the questions with the total score of the test was calculated to be in the range of 0.41 to 0.73 , which is considered optimal based on the guidelines by Nunnally and Bernstein (1994). Also, in the present study, the value of both Cronbach's alpha and Omega McDonald's coefficients for the whole scale was estimated to be 0.92 .

\section{Anxiety Sensitivity Index}

Killgore, Sonis, Rosso, and Rauch (2016) define anxiety sensitivity as "the propensity to fear the somatic, mental, and social consequences of anxiety,(which) is associated with an elevated risk of developing anxiety disorders" (p. 23). Anxiety Sensitivity Index (ASI) was developed by Taylor et al. (2007) to measure people's sensitivity to anxiety. The tool has 18 items that address a person's fears about the symptoms associated with anxiety arousal in three main components namely, physical concerns (e.g., " When my stomach is upset, I worry that I might be seriously ill "), cognitive concerns: example: "When I have trouble thinking clearly, I worry that there is something wrong with me ") and social concerns (e.g.: "I worry that other people will notice my anxiety "). All of these codes are encoded on a 5-point Likert scale from "very little" equivalent to 0 to "very high" equivalent to 4 . Taylor et al. (2007) used confirmatory factor analysis, convergent validity, discriminant validity, and criterion-related validity to examine the internal validity of the instrument and Cronbach's alpha coefficient for its internal reliability. The Cronbach's alpha coefficient of three scales has been reported to be favorable in the study of Taylor et al. (2007), Wheaton et al. (2012), Blakey et al. (2015), and Blakey and Abramowitz (2017) and in the range of 0.78 to 0.90 . The psychometric characteristics of the Persian version of this questionnaire have also been reported to be desirable in the Iranian research community (e.g., Agah Haris \& Ramezani, 2019). In the present study, the alpha value for the three subscales of physical concerns, cognitive and social concerns was calculated to be $0.87,0.86$, and 0.76 , respectively.

\section{Social Trust Questionnaire}

This questionnaire was developed by Saffarinia and Sharif (2013) to measure social trust in the Iranian society. The tool is based on Johnson's (1993) theory and has 25 items, all coded on a 5-point Likert from "completely disagree" equivalent to 1 to "strongly agree" equivalent to 5 . To test the validity of the questionnaire, the scale developers used factor analysis to determine the main components and applied Cronbach's alpha coefficient to check its internal consistency. A conceptual structure with five factors was detected: trustbased behavior (example: "I believe that no one can be trusted in our time", desire for cooperation (example: "I am interested in cooperating with others in social and economic fields"), Frankness (example: "I think in our society, men are more secure than women"), honesty (example: "I believe that our people are more likely to be involved because of dishonesty and differences and finally reliability (for example, "I usually trust the commitment or verbal promise of others"). All 
Cronbach's alpha coefficients for the subscales of the questionnaire were reported to be higher than 0.90 . In this study, the Cronbach's alpha coefficients for the five subscales fall in the range of 0.68 to 0.83 . The McDonald omega's value for the entire scale was 0.67 .

\section{Health Anxiety List}

This scale was developed by Salkovskis, Rimes, Warwick, and Clark (2002) to measure people's health concerns, their awareness of body emotions or changes, and their fear of the consequences of an illness. The tool has 18 multiple-choice items, and the options for each item are coded on a Likert scale from 0 to 3. For example, item 3 of this tool has options " As a rule, I am not aware of bodily sensations or changes " equivalent to 0 , "Sometimes I am aware of bodily sensations or changes " equivalent to 1, "I am often aware of bodily sensations or changes " equivalent to 2 and "I am constantly aware of bodily sensations or changes". In a study by Salkovskis et al. (2002), the test-retest coefficient of this instrument was in the range of 0.76 to 0.90 and Cronbach's alpha coefficient was reported to be 0.95 . In Blakey and Abramowitz's (2017), Cronbach's alpha coefficient for this questionnaire was calculated and reported as 0.85 . Its psychometric properties have been reported in Iranian research too (Nargesi, Izadi, Kariminejad, \& Rezaii Sharif, 2017) and confirm a three-factor component (disease, physical consequences, and general health concerns) in its Persian version In the present study, Cronbach's alpha and Omega McDonald's coefficients for this tool were 0.81 and 0.82 , respectively. It should be noted that only scores related to the general health anxiety subscale were used in this study.

\section{Corona Facts Quiz}

This tool measures people's general knowledge about Coronavirus and its transmission methods. It has 7 items that were published on March 4, 2020, on the website of the Center for Disease Control and Prevention entitled "Share the Realities of COVID-19". This tool has 7 items that are scored on a two-point Likert containing incorrect (equivalent to 0 ) and correct (equivalent to 1 ).

\section{Trust in National Action in the Face of Corona Inventory}

In the present study, four items (such as "In Iran, all necessary measures have been taken to prevent the high prevalence of corona") have been used to measure the Iranian students' confidence in national measures taken in the face of the corona. All four items contain general statements about the measures and question Iran's medical facilities in the face of the prevalence of Covid-19.
Participants were asked to express their views in the form of choosing one of the two options, I agree (equivalent to 1 ) and I disagree (equivalent to 0 ). Cronbach's alpha coefficient for this inventory was 0.71 and the correlation coefficient of its items with the total score is in the range of 0.45 to 0.74 , which is considered to be desirable based on the guidelines by Nunnally and Bernstein (1994). The omega coefficient was equal to 0.70 .

\section{Data Analyses}

SPSS package version 22 and JASP-0.9 software were used to analyze the data for this study. Prior to analyses, the variables were examined in terms of the existence of univariate and multivariate outliers scatter data. Furthermore, the assurance of the necessary assumptions for multiple regressions was examined. Pearson correlation coefficient was used to investigate the relationship between corona anxiety and other research variables. Also, multiple regression analysis was used to evaluate the predictive power of corona anxiety.

\section{Results}

Table 1 reports descriptive indicators including mean, standard deviation, minimum value, and maximum value for research variables. Also, as the table shows, all values related to the two indices of skewness and kurtosis are in the range of -1 to +1 . As a result, according to the proposed model of Meyers, Gamst, and Guarino (2006), it can be concluded that the distribution of all research variables is normal.

Pearson correlation coefficient has been used to investigate the relationship between corona anxiety and other research variables. As shown in Table 2, Corona Anxiety is positively and significantly correlated with physical, cognitive, and social components of anxiety sensitivity; corona facts test scores, and overall health concerns. However, the relationship between the honesty component of the Social Trust Questionnaire and the confidence in the national actions taken in the face of Corona is significantly negative.

Multiple regression analysis has also been used to evaluate the predictive power of corona anxiety. The regression equation formed in this analysis is significant $(\mathrm{F}(11.250)=6.21$, $p<0.001$ ) and explains approximately $22 \%$ of the variance in corona anxiety scores. As can be seen in Table 3, among the predictor variables, five variables were able to predict the significance of Corona anxiety: physical component of anxiety sensitivity, the component of honesty in the social trust questionnaire, Corona reality test scores, confidence in national measures taken in facing corona and finally general health concerns. Precisely, sensitivity to physical anxiety, corona 
Table 1 Study measure descriptive statistics

\begin{tabular}{lllllll}
\hline Measure & M & (SD) & Min & Max & skew & kurtosis \\
\hline Coronavirus anxiety inventory & 32.96 & $(4.99)$ & 14 & 45 & -0.92 & 0.99 \\
Anxiety sensitivity inventory-3: physical concerns & 7.96 & $(4.99)$ & 0 & 21 & 0.36 & -0.36 \\
Anxiety sensitivity inventory-3: cognitive concerns & 8.14 & $(4.91)$ & 0 & 22 & 0.40 & -0.49 \\
Anxiety sensitivity inventory-3: social concerns & 9.06 & $(4.43)$ & 0 & 22 & 0.24 & -0.24 \\
Social trust questionnaire: trust-based behavior & 17.60 & $(2.91)$ & 10 & 25 & -0.22 & -0.25 \\
Social trust questionnaire: collaborative tendencies & 20.13 & $(2.70)$ & 11 & 25 & -0.26 & 0.06 \\
Social trust questionnaire: clarity & 16.81 & $(1.68)$ & 11 & 21 & -0.05 & 0.03 \\
Social trust questionnaire: honesty & 16.63 & $(1.97)$ & 11 & 23 & 0.22 & 0.44 \\
Social trust questionnaire: confidence & 13.97 & $(2.68)$ & 5 & 23 & -0.01 & 0.30 \\
Corona fact quiz & 6.34 & $(0.83)$ & 3 & 7 & -0.90 & 0.93 \\
Trust in national action in the face of Corona inventory & 1.33 & $(1.19)$ & 0 & 4 & 0.82 & -0.15 \\
Short health anxiety inventory: general concerns & 7.67 & $(2.78)$ & 2 & 17 & 0.64 & 0.58 \\
\hline
\end{tabular}

facts, and general health concerns have positive and meaningful associations $(\beta=0.21, \mathrm{p}<0.01, \beta=0.15, \mathrm{p}<0.01$, and $\beta=0.25, p<0.0001$, respectively), whereas honesty and trust in national measures have negatively predicted corona anxiety ( $\beta=-0.14, p<0.02$, and $\beta=-0.13, p<0.03$, respectively).

Table 3 also provides a semi-partial correlation for all predictor variables. Semi partial correlation of five significant predictors of sensitivity to physical anxiety, honesty, Corona realities, confidence in national measures taken in the face of
Corona, and overall health concerns is $0.16,0.11,0.16,0.13$, and 0.24 respectively. These values indicate that the above predictions predict $2.6 \%, 1.2 \%, 2.6 \%, 1.7 \%$, and $5.8 \%$ of the variance in corona anxiety scores, respectively. Table 3 also shows that the values for the two indices of tolerance and variance inflation factor (VIF) are in the appropriate range proposed by Meyers et al. (2006), which means that there is no multicollinearity problem in relation to the variables predicting the regression.

Table 2 Bivariate correlations between study measures

\begin{tabular}{|c|c|c|c|c|c|c|c|c|c|c|c|}
\hline & CAI & ASI-P & ASI-C & ASI-S & $\begin{array}{l}\text { STQ- } \\
\mathrm{T}\end{array}$ & $\begin{array}{l}\text { STQ- } \\
\text { COL }\end{array}$ & $\begin{array}{l}\text { STQ- } \\
\text { CL }\end{array}$ & $\begin{array}{l}\text { STQ- } \\
\mathrm{H}\end{array}$ & $\begin{array}{l}\text { STQ- } \\
\text { CON }\end{array}$ & CFQ & NAC \\
\hline ASI-P & $0.31^{* * *}$ & - & & & & & & & & & \\
\hline ASI-C & $0.21^{* *}$ & $0.68^{* *}$ & - & & & & & & & & \\
\hline ASI-S & $0.20^{* *}$ & $0.56^{* *}$ & $0.60^{* *}$ & - & & & & & & & \\
\hline STQ-T & -0.04 & -0.07 & -0.08 & -0.03 & - & & & & & & \\
\hline STQ-COL & 0.10 & 0.05 & $0.12^{*}$ & 0.03 & $0.21^{* *}$ & - & & & & & \\
\hline STQ-CL & 0.07 & 0.01 & 0.05 & 0.05 & -0.03 & 0.06 & - & & & & \\
\hline STQ-H & $-0.17^{* *}$ & $-0.20^{* * *}$ & $-0.22^{* *}$ & $-0.20^{* *}$ & $0.19^{* *}$ & 0.09 & -0.03 & - & & & \\
\hline STQ-CON & -0.04 & -0.02 & $-0.15^{*}$ & 0.02 & $0.32^{* *}$ & 0.10 & $-0.19^{* *}$ & $0.12^{*}$ & - & & \\
\hline CFQ & $0.12^{*}$ & 0.00 & -0.01 & -0.02 & 0.09 & 0.05 & -0.04 & $0.12^{*}$ & $0.13^{*}$ & - & \\
\hline TNAC & $-0.13^{*}$ & 0.09 & 0.00 & 0.09 & $0.17^{* *}$ & 0.04 & 0.06 & $0.14^{*}$ & $0.25^{* *}$ & 0.07 & - \\
\hline SHAY-G & $0.35^{* *}$ & $0.42^{* *}$ & $0.31^{* *}$ & $0.22^{* *}$ & $-0.13^{*}$ & 0.06 & -0.01 & $-0.13^{*}$ & 0.01 & -0.05 & -0.11 \\
\hline
\end{tabular}

Note. CAI Coronavirus anxiety inventory, ASI-P Anxiety sensitivity inventory-3 physical concerns subscale, ASI-C Anxiety sensitivity inventory-3 cognitive concerns subscale, ASI-S Anxiety sensitivity inventory-3 social concerns subscale, STQ-T Social trust questionnaire trust-based behavior subscale, STQ-COL Social trust questionnaire collaborative tendencies subscale, STQ-CL Social trust questionnaire clarity subscale, STQ-H Social trust questionnaire honesty subscale, STQ-CON Social trust questionnaire confidence subscale, CFQ Corona fact quiz, TNACTrust in national action in the face of Corona inventory, SHAY-G Short health anxiety inventory general concerns subscale.

$* p<0.05$

$* * p<0.01$ 
Table 3 Multiple regression predicting Coronavirus anxiety

\begin{tabular}{lllllllll}
\hline Variable & $\mathrm{B}$ & $\mathrm{SE}$ & $\beta$ & $\mathrm{t}$ & $\mathrm{P}$ & $\mathrm{Spr}$ & Tol & $\mathrm{VIF}$ \\
\hline ASI-P & 0.21 & 0.08 & 0.21 & 2.52 & 0.01 & 0.16 & 0.45 & 2.24 \\
ASI-C & -0.08 & 0.09 & -0.08 & -0.91 & 0.37 & -0.06 & 0.44 & 2.27 \\
ASI-S & 0.07 & 0.08 & 0.06 & 0.85 & 0.40 & 0.05 & 0.58 & 1.72 \\
STQ-T & 0.05 & 0.11 & 0.03 & 0.46 & 0.64 & 0.03 & 0.82 & 1.22 \\
STQ-COL & 0.16 & 0.11 & 0.09 & 1.48 & 0.14 & 0.09 & 0.91 & 1.09 \\
STQ-CL & 0.21 & 0.17 & 0.07 & 1.19 & 0.23 & 0.07 & 0.94 & 1.07 \\
STQ-H & -0.27 & 0.11 & -0.14 & -2.49 & 0.02 & -0.11 & 0.89 & 1.14 \\
STQ-CON & -0.06 & 0.12 & -0.03 & -0.53 & 0.59 & -0.03 & 0.78 & 1.28 \\
CFQ & 0.88 & 0.34 & 0.15 & 2.58 & 0.01 & 0.16 & 0.97 & 1.03 \\
TNAC & -0.54 & 0.25 & -0.13 & -2.13 & 0.03 & -0.13 & 0.88 & 1.14 \\
SHAY-G & 0.45 & 0.11 & 0.25 & 3.97 & 0.001 & 0.24 & 0.78 & 1.28 \\
\hline
\end{tabular}

Note. CAI Coronavirus anxiety inventory, ASI-P Anxiety sensitivity inventory-3 physical concerns subscale, ASI-C Anxiety sensitivity inventory-3 cognitive concerns subscale, ASI-S Anxiety sensitivity inventory-3 social concerns subscale, STQ-T Social trust questionnaire trust-based behavior subscale, STQ-COL Social trust questionnaire collaborative tendencies subscale, STQ-CL Social trust questionnaire clarity subscale, STQ-H Social trust questionnaire honesty subscale, STQ-CON Social trust questionnaire confidence subscale, CFQ Corona fact quiz, TNACTrust in national action in the face of Corona inventory, SHAY-G Short health anxiety inventory general concerns subscale.

Spr- semi partial correlation, Tol- Tolerance

\section{Discussion}

The present study sought to investigate the psychological factors that seemed to be effective in arousing people's anxiety in response to COVID-19. As mentioned, previous research suggests that three categories of factors are associated with anxiety resulting from the spread of a viral illness in individuals. The first two categories have been identified directly from studies (such as Blakey \& Abramowitz, 2017; Blakey et al., 2015; Wheaton et al., 2012) that examine people's anxiety in the face of outbreaks of Zika, Ebola, swine flu, and SARS. The third category, however, refers to studies (such as Bauer et al., 2020; Blair et al., 2017; Killgore et al., 2020) that address the need for trust and social participation in a crisis resulting from an illness or in coordination with public health policies. Findings of the present study indicate the existence of a relationship between variables from all three categories with anxiety caused by COVID-19 in a sample of young Iranian adults.

As the results of the regression analysis show, confidence in the national measures taken in the face of corona prevalence has led to a negative and significant prediction of coronainduced anxiety. Thus, trust in the government, besides the ability to lead individuals to follow government programs, policies, and health recommendations when a disease spreads (Blair et al., 2017; Salmon et al., 2005) can predict anxiety reduction caused by a disease outbreak. The findings of the present study show that in addition to trust in national measures taken in the face of the corona, people's belief in honesty in society may also emerge as a significant predictor of corona-induced anxiety.
As mentioned, this component of social trust includes phrases such as "I believe that our people are more likely to quarrel and disagree because of their dishonesty". The results of the regression analysis show that such beliefs have a negative and significant relationship with anxiety caused by corona prevalence. In other words, when data from the present study was collected, high scores of corona-related anxiety were reported by students who were less likely to believe in honesty in the interpersonal relationships of today's Iranian society. In fact, it seems that the belief in the lack of honesty at the community level has added to the ambiguity and complexity of the critical situation caused by the Corona outbreak, which has resulted in increased student anxiety.

Overall, our findings show that the psychological factors identified in previous research are also effective in relieving anxiety caused by the prevalence of corona. As the results of the regression analysis show, the set of predictor variables present in this study explains a total of $22 \%$ of the variance in the variable of corona anxiety criterion. This is an acceptable percentage considering Blakey and Abramowitz (2017) as well as Blakey et al. (2015)'s results which explained a $27 \%$ variance of Ebola anxiety. Moreover, based on the results of the regression analysis conducted in the present study, it was revealed that the general health concern has the largest share in predicting the anxiety of students regarding the prevalence of Coronavirus. In other words, in the first week after the cancellation of university classes and students' return to their families, the highest degree of anxiety caused by Corona was reported among students who were more concerned about their health compared to normal circumstances. This seems 
quite logical and predictable considering the definition of health anxiety and its consequences. As mentioned earlier, health anxiety has roots in an individual's beliefs and mental presuppositions about physical symptoms as well as the course and treatment of an illness, and has the potential to trigger a mental illness when one hears about a particular illness (Marcus et al., 2007). It is worth mentioning that the predictive power of this variable for anxiety has also been confirmed in Wheaton et al. (2012) in the swine flu case.

After general health concerns, the two variables predicting anxiety sensitivity (physical component) and knowledge of corona facts had the same position in predicting anxiety associated with corona prevalence. As mentioned earlier, those with a high score on anxiety sensitivity constantly monitor their physical changes, and as a result may show a more severe anxiety response to the spread of various diseases (Blakey \& Abramowitz, 2017). Therefore, it seems logical that in the present study, high anxiety scores in the face of corona prevalence have been reported more by those who are more sensitive to anxiety in normal situations.

In addition, the positive and significant predictive power of Corona-based knowledge suggests that students who are more familiar with the facts published by the World Health Organization about the COVID-19 pandemic have reported greater anxiety about the spread of the virus. In fact, as we have seen in Blakey and Abramowitz (2017), the importance of collecting information about the incidence of disease whether consistent (i.e., gathering the right information from official sources) or inconsistent (such as seeking reassurance) is quite evident. In addition, this implicitly demonstrates that accurate and up-to-date medical information about Coronavirus in the first few weeks of its spread has aroused beneficial and effective anxiety to face the SARS-CoV-2 virus. In other words, previous research (for example, Tausczik, Faasse, Pennebaker, and Petrie (2012) shows that in the first weeks after the news of a virus spread, people look for information from official and unofficial sources. Therefore, if official sources disseminate reliable information, it can be hoped that effective anxiety will be aroused in individuals, which will eventually lead to further cooperation with health care providers in the context of epidemics such as COVID-19.

However, it should be noted that knowledge of the realities of a virus in this study, similar to Blakey and Abramowitz (2017)'s study on anxiety over the prevalence of Zika, is one of the variables that was classified as the second category of factors affecting anxiety caused by the prevalence of a virus which was considered as a meaningful prediction. Therefore, as mentioned in the introduction, it is necessary to study the variables that fall into the third category, namely public trust about the anxiety caused by the SARS-CoV-2 virus and the unprecedented condition associated with it (Shigemura et al., 2020). In relation to the latter, our findings show a significant effect of the variables related to the third category on anxiety caused by the prevalence of corona.

\section{Limitations and Suggestions for Further Research}

The present study's sample consisted of students who had not experienced any of their relatives infected with the SARSCoV-2 virus between March 11 to 18, 2020. In addition, these students were selected from Salman Farsi University of Kazerun in Fars Province, which according to the Iranian Ministry of Health reports is not known as the main center of corona prevalence in Iran. Thus, it can be concluded that the first limitation of the present study was the study of a part of Iranian students who, at least until the data gathering step, had no direct experience with the SARS-CoV-2 virus. In addition, the study was conducted at a time when, despite the closure of university classes and the relative vigilance of the community, strict national policies on controlling the prevalence of the COVID-19 were not at work. Therefore, in order to understand the emotional experiences of the Iranian society regarding the prevalence of Coronavirus, one should look forward to the results of research that will gather its information after adopting these policies, especially during times of travel restrictions and home quarantine. In line with anxiety about the prevalence of corona, further studies can examine individuals' compatibility with home quarantine, and in particular the impact of coping strategies on Coronavirus anxiety.

Acknowledgments We would like to thank the two anonymous reviewers for their careful reading of our manuscript and their many insightful comments and suggestions.

Data Availability The datasets generated during and/or analyzed during the current study are available from the corresponding author on reasonable request.

\section{Compliance with Ethical Standards}

Conflict of Interest On behalf of all authors, the corresponding author states that there is no conflict of interest.

Ethical Approval Procedures performed in studies involving human participants were in accordance with the ethical standards of the institutional and/or national research committee and with the 1964 Helsinki declaration and its later amendments or comparable ethical standards. Informed Consent Informed consent was obtained from all individual participants included in the study.

\section{References}

Agah Haris, M., \& Ramezani, N. (2019). Comparing personality traits and anxiety sensitivity among patients with and without psoriasis. Health Psychology, 7(4), 67-82 In Farsi. 
Bauer, L, L., Seiffer, B., Deinhart, C., Atrott, B., Sudeck, G., Hautzinger, M., Rösel, I., \& Wolf, S. (2020). Associations of exercise and social support with mental health during quarantine and social-distancing measures during the COVID-19 pandemic: A cross-sectional survey in Germany. MedRxiv (present server for health science). https:// doi.org/10.1101/2020.07.01.20144105.

Becker, M. H., \& Janz, N. K. (1984). The health belief model: A decade later. Health Education Quarterly, 11, 1-47.

Blair, R. A., Morse, B. S., \& Tsai, L. L. (2017). Public health and public trust: Survey evidence from the Ebola virus disease epidemic in Liberia. Social Science and Medicine, 72, 89-97.

Blakey, S. M., \& Abramowitz, J. S. (2017). Psychological predictors of health anxiety in response to the Zika virus. Journal of Clinical Psychology in Medical Settings, 24, 270-278. https://doi.org/10. 1007/s10880-017-9514-y.

Blakey, S. M., Reuman, L., Jacoby, R. J., \& Abramowitz, J. S. (2015). Tracing "Fearbola": Psychological predictors of anxious responding to the threat of Ebola. Cognitive Therapy Research, 39, 816-825. https://doi.org/10.1007/s10608-015-9701-9.

Brooks, S. K., Webster, R. K., Smith, L. E., Woodland, L., Wessely, S., Greenberg, N., \& Rubin, G. J. (2020). The psychological impact of quarantine and how to reduce it: Rapid review of the evidence. The Lancet, 395, 912-920.

Chen, X., \& Wan, P. (2019). Social trust and corporate social responsibility: Evidence from China. Corporate Social Responsibility and Environmental Management, 27(2), 485-500.

Evans, O. (2020). Socio-economic impacts of novel coronavirus: The policy solutions. BizEcons Quarterly, 7, 3-12.

Killgore, W., Sonis, L. A., Rosso, I. M., \& Rauch, S. L. (2016). Emotional intelligence partially mediates the association between anxiety sensitivity and anxiety symptoms. Psychological Reports, 118(1), 23-40. https://doi.org/10.1177/0033294115625563.

Killgore, W. D., Taylor, E. C., Cloonan, S. A., \& Dailey, N. D. (2020). Psychological resilience during the COVID-19 lockdown. Psychiatry Research, 291, 113-216. https://doi.org/10.1016/j. psychres.2020.113216.

Larson, H. J., \& Heymann, D. L. (2010). Public health response to influenza a (H1N1) as an opportunity to build public trust. Journal of the American Medical Association, 303(2), 271-272.

Liao, Q., Cowling, B. J., Lam, W. W. T., \& Fielding, R. (2011). The influence of social-cognitive factors on personal hygiene practices to protect against influenzas: Using modeling to compare avian a/ H5N1 and 2009 pandemic a/H1N1 influenzas in Hong Kong. International Journal of Behavioral Medicine, 18, 93-104.

Lovari, A. (2020). Spreading (dis)trust: Covid-19 misinformation and government intervention in Italy. Media and Communication, 8(2), 458-461. https://doi.org/10.17645/mac.v8i2.3219.

Marcus, D. K., Gurley, J. R., Marchi, M. M., \& Bauer, C. (2007). Cognitive and perceptual variables in hypochondriasis and health anxiety: A systematic review. Clinical Psychology Review, 27, $127-139$.

Marlow, L. A. V., Waller, J., \& Wardle, J. (2007). Trust and experience as predictors of HPV vaccine acceptance. Human Vaccines, 3(5), 171175.

Meyers, L. S., Gamst, G., \& Guarino, A. J. (2006). Applied multivariate research: Design and interpretation. Thousand Oaks: Sage Publications.

Nargesi, F., Izadi, F., Kariminejad, \& Rezaii Sharif, A. (2017). The investigation of the reliability and validity of the Persian version of the Health anxiety questionnaire in students of Lorestan University of Medical Sciences. Quarterly of Educational Measurement, 7(27), 147-160. In Farsi. https://doi.org/10.22054/JEM.2017.19621.1495.

Nunnally, J., \& Bernstein, I. (1994). Psychometric theory. New York: McGraw-Hill.
Pramiyanti, A., Mayangsari, I., Nuraeni, R., \& Firdaus, Y. D. (2020). Public perception on transparency and Trust in Government Information Released during the COVID-19 pandemic. Asian Journal for Public Opinion Research, 8(3), 351-376. https://doi. org/10.15206/ajpor.2020.8.3.351.

Reiss, S., \& McNally, R. J. (1985). Expectancy model of fear. In S. Reiss \& R. R. Bootzin (Eds.), Theoretical issues in behavior therapy (pp. 107-121). San Diego, CA: Academic Press.

Saffarinia, M., \& Sharif, N. (2013). Construction and psychometrics characteristics of social trust questionnaire. Social Psychology Research, 3(11), 47-57 In Farsi.

Salkovskis, P. M., \& Warwick, H. C. (1986). Morbid preoccupations, health anxiety, and reassurance: A cognitive-behavioral approach to hypochondriasis. Behavior Research and Therapy, 24, 597-602.

Salkovskis, P. M., \& Warwick, H. C. (2001). Meaning, misinterpretations, and medicine: A cognitive-behavioral approach to understanding health anxiety and hypochondriasis. In V. Starcevic \& D. R. Lipsitt (Eds.), Hypochondriasis: Modern perspectives on an ancient malady (pp. 202-222). New York: Oxford University Press.

Salkovskis, P. M., Rimes, K. A., Warwick, H. M. C., \& Clark, D. M. (2002). The health anxiety inventory: Development and validation of scales for the measurement of health anxiety and hypochondriasis. Psychological Medicine, 32, 843-853.

Salmon, D. A., Moulton, L. H., Omer, S. B., DeHart, M. P., Stokley, S., \& Halsey, N. A. (2005). Factors associated with refusal of childhood vaccines among parents of school-aged children: A case-control study. Archives of Pediatrics and Adolescent Medicine, 159(5), 470-476.

Shigemura, J., Ursano, R. J., Morganstein, J. C., Kurosawa, M., \& Benedek, D. M. (2020). Public responses to the novel 2019 coronavirus (2019-nCoV) in Japan: Mental health consequences and target populations. Psychiatry Clinical Neuroscience., 74, 281-282. https://doi.org/10.1111/pcn.12988.

Tausczik, Y., Faasse, K., Pennebaker, J. W., \& Petrie, K. J. (2012). Public anxiety and information seeking following the H1N1 outbreak: Blogs, newspaper articles, and Wikipedia visits. Health Communication, 27, 179-185.

Taylor, S., \& Asmundson, G. J. G. (2004). Treating health anxiety: A cognitive-behavioral approach. New York: Guilford Press.

Taylor, S., Zvolensky, M., Cox, B., Deacon, B., Heimberg, R., Ledley, D. R., et al. (2007). Robust dimensions of anxiety sensitivity: Development and initial validation of the anxiety sensitivity Index3 (ASI-3). Psychological Assessment, 19, 176-188.

Welch, M. R., Rivera, R. E., Conway, B. P., Yonkoski, J., Lupton, P. M., \& Giancola, R. (2005). Determinants and consequences of social trust. Sociological Inquiry, 75(4), 453-473.

Wheaton, M. G., Abramowitz, J. S., Berman, N. C., Fabricant, L. E., \& Olatunji, B. O. (2012). Psychological predictors of anxiety in response to the H1N1 (swine flu) pandemic. Cognitive Therapy and Research, 36, 210-218.

Whetten, K., Leserman, J., Whetten, R., Ostermann, J., Thielman, N., Swartz, M., \& Stangl, D. (2006). Exploring lack of trust in care providers and the government as a barrier to health service use. American Journal of Public Health, 96(4), 716-721.

Wilder-Smith, A., \& Freedman, D. O. (2020). Isolation, quarantine, social distancing, and community containment: Pivotal role for old-style public health measures in the novel coronavirus (2019-nCoV) outbreak. Journal of Travel Medicine, 27(2). https://doi.org/10.1093/ $\mathrm{jtm} / \mathrm{taaa} 020$.

World Health Organization (WHO). (2020). Coronavirus disease (COVID-19) outbreak situation. Retrieved from https://www.who. int/emergencies/diseases/novel-Coronavirus-2019. Accessed 10 June 2020 
Xie, X.-F., Stone, E., Zheng, R., \& Zhang, R.-G. (2011). The 'Typhoon eye Effect': Determinants of distress during the SARS epidemic. Journal of Risk Research., 14(9), 1091-1107. https://doi.org/10. 1080/13669877.2011.571790.

Xiong, J., Lipsitz, O., Nasri, F., Lui, L. M. W., Gill, H., et al. (2020). Impact of COVID-19 pandemic on mental health in the general population: A systematic review. Journal of Affective Disorders., 277, 55-64. https://doi.org/10.1016/j.jad.2020.08.001.

Publisher's Note Springer Nature remains neutral with regard to jurisdictional claims in published maps and institutional affiliations. 